This document is confidential and is proprietary to the American Chemical Society and its authors. Do not copy or disclose without written permission. If you have received this item in error, notify the sender and delete all copies.

\title{
A Combined Optoelectronic and Electrochemical Study of Nitrogenated Carbon Electrodes
}

\begin{tabular}{|r|l|}
\hline Journal: & The Journal of Physical Chemistry \\
\hline Manuscript ID & jp-2016-10145g.R2 \\
\hline Danuscript Type: & Article \\
\hline Complete List of Authors: & $\begin{array}{l}\text { Behan, James; Trinity College Dublin, School of Chemistry } \\
\text { Stamatin, Serban; J. Heyrovský Institute of Physical Chemistry, Academy } \\
\text { of Sciences of the Czech Republic, } \\
\text { Hoque, Md. Khairul; Trinity College Dublin, School of Chemistry } \\
\text { Ciapetti, Guido; Trinity College Dublin, School of Chemistry } \\
\text { Zen, Federico; Trinity College Dublin, School of Chemistry } \\
\text { Esteban-Tejeda, Leticia; University of Dublin Trinity College } \\
\text { Colavita, Paula; Trinity College Dublin, School of Chemistry }\end{array}$ \\
\hline
\end{tabular}




\title{
A Combined Optoelectronic and Electrochemical Study of Nitrogenated Carbon Electrodes
}

\author{
James A. Behan, Serban N. Stamatin, Md. Khairul Hoque, Guido Ciapetti, Federico Zen, Leticia \\ Esteban-Tejeda and Paula E. Colavita* \\ School of Chemistry, CRANN and AMBER Research Centres, Trinity College Dublin, College \\ Green, Dublin 2, Ireland.
}

*Email: colavitp@tcd.ie 


\section{Abstract}

The modification of carbon materials via the incorporation of nitrogen has received much attention in recent years due to their performance as electrodes in applications ranging from electroanalysis to electrocatalysis for energy storage technologies. In this work we synthesized nitrogen-incorporated amorphous carbon thin film electrodes $(\mathrm{a}-\mathrm{C}: \mathrm{N})$ with different degrees of nitrogenation via magnetron sputtering. Electrodes were characterized using a combination of spectroscopic and electrochemical methods, including X-ray photoelectron spectroscopy, ellipsometry, voltammetry and impedance spectroscopy. Results indicate that low levels of nitrogenation yield carbon materials with narrow optical gaps and semimetallic character. These materials displayed fast electron-transfer kinetics to hexammine ruthenium(II)/(III), an outersphere redox couple that is sensitive to electronic properties near the Fermi level in the electrode material. Increasing levels of nitrogenation first decrease the metallic character of the electrodes and increase the impedance to charge transfer and, ultimately, yield materials with optical and electrochemical properties consistent with disordered cluster aggregates rather than amorphous solids. A positive correlation was found between the resistance to charge transfer and the optical gap when using the outer sphere redox couple. Interestingly, the use of ferrocyanide as a surfacesensitive redox probe resulted in a monotonic increase of the impedance to charge transfer vs. nitrogen content. This result suggests that surface chemical effects can dominate the electrochemical response, even when nitrogenation results in enhanced metallic character in carbon electrodes. 


\section{Introduction}

The incorporation of heteroatoms such as nitrogen into carbon frameworks and its effects on carbon properties has received much attention over the past few decades. The initial research mostly focused on the effects of nitrogenation for electronic and mechanical applications of carbon coatings and thin-films. ${ }^{1,2}$ More recently, there has been growing interest in understanding the effects of nitrogenation on the properties of carbon electrode materials, given their importance for applications in electroanalysis, ${ }^{3-5}$ electrocatalysis, ${ }^{3,6}$ and as support materials in fuel cells. ${ }^{7}$ Nitrogen incorporation can significantly affect bulk carbon properties; as reported by several groups, ${ }^{1,2}$ substitutional $\mathrm{N}$-sites within a graphitic carbon matrix introduce donor states that can impart n-type conductivity and enhance overall charge transport while they can also modulate mechanical stress and defects in the carbon structure. Surface effects of nitrogenation however are also important, particularly for applications in electrochemistry which rely on processes that occur at the carbon interface.

Nitrogenated carbon thin film electrodes have been shown to display large $(>3 \mathrm{~V})$ potential windows and low background current in aqueous solutions, as well as low roughness, which are important requirements for electroanalytical applications. ${ }^{3-5,8}$ The above favourable properties have led to applications in the detection of heavy metals in solution, as well as the detection of biomolecules such as estrone, dopamine and ascorbate. ${ }^{9-11}$ Nitrogenation has been shown in many cases to accelerate the kinetics of electron transfer, resulting in enhanced peak currents and/or a narrowing of the peak potential separation. The precise mechanism of enhancement is not well understood although it has been speculated that improved electronic properties and/or interactions between the analyte molecules and surface chemical groups contribute to the observed enhancements. $^{12}$ 
Nitrogenated carbon electrodes are intensely studied for multi-step electron-proton coupled reactions, such as hydrogen peroxide production from water ${ }^{13,14}$ and the oxygen reduction reaction (ORR). ${ }^{15-18}$ Nitrogenated carbons have shown remarkable activity in the ORR, which is the cathode reaction in fuel cells and Li-air batteries. Their activity has been attributed to the presence of specific surface sites such as substitutional and pyridinic nitrogen, ${ }^{18-25}$ which alter the surface charge density and Lewis basicity. Heteroatom doping can also result in structural changes in the carbon scaffold that impact its surface chemistry, such as increased defect and edge-plane exposure. Defect creation via nitrogen incorporation has, for instance, been shown to improve Li storage capacity, ${ }^{26}$ and greater edge exposure is known to enhance charge transfer rates and catalytic activity. ${ }^{24,27-32}$ Furthermore, nitrogenation offers a route for increasing the density of states resulting in higher capacitance, an effect that has been leveraged in the fabrication of supercapacitors. ${ }^{33}$

The effects of nitrogenation on bulk electronic properties, surface chemistry and structural disorder in the carbon network are often interrelated making it challenging to discern or predict the overall effect of nitrogenation on the electrochemical properties of carbon electrodes. Recent studies in the literature have successfully established structure-activity relationships for undoped carbon materials resulting in useful insights on how to predict interfacial redox chemistry based on bulk electronic structure. This has been shown for instance in the case of materials with long range order or high crystallinity, such as nanotubes, graphene and graphite ${ }^{34-41}$ However, less is known about carbon materials which lack long-range order despite them being widely used by the electrochemical community.

Optical characterization methods offer the possibility of discriminating between bulk and surface effects of nitrogenation. However, despite the obvious general interest and wide 
applications of nitrogen-doped electrodes, their electrochemical properties have not yet been studied in relation to their bulk optoelectronic properties. In this work we present a combined optical and electrochemical characterization study of the interplay between the bulk optoelectronic properties and the electrochemical properties of nitrogenated amorphous carbon $(\mathrm{a}-\mathrm{C}: \mathrm{N})$ thin film electrodes. Thin film electrodes have recently enabled the study of electrode properties of nitrogenated carbons, ${ }^{42-45}$ independently from potentially confounding variables that might affect studies at particle/ink electrodes, such as porosity, packing, binders and metal impurities. Nitrogenated amorphous carbon $(\mathrm{a}-\mathrm{C}: \mathrm{N})$ films were synthesized with varying nitrogen content via DC magnetron sputtering. Carbon materials were characterized using a combination of optical and electrochemical techniques, including spectroscopic ellipsometry (SE), X-Ray Photoelectron Spectroscopy (XPS), Cyclic Voltammetry (CV) and Electrochemical Impedance Spectroscopy (EIS). Results indicated that low levels of nitrogenation produce a-C:N films with greater metallic character than non-nitrogenated materials (a-C), which translates into faster electron-transfer rates at the carbon-electrolyte interface. High levels of nitrogen incorporation, on the other hand, result in films with characteristics more typical of cluster aggregates than amorphous solids. Electrochemical studies on these materials using both outersphere and surface-sensitive redox probes allow for the discrimination of electronic and surface effects resulting from nitrogen incorporation

\section{Experimental Methods}

Materials. Hexaammine Ruthenium (II) Chloride (99.9\%, trace metals), Hexaammine Ruthenium (III) Chloride (98\%), Potassium Chloride (Bioxtra, >99.0\%), Sulfuric Acid (95- 
97\%), Hydrogen Peroxide (>30\% w/v) Potassium Ferrocyanide (Analar, $>99.0 \%$ ) and methanol (semiconductor grade) were used without further purification.

Substrate Preparation. B-Doped Silicon wafers (MicroChemicals; resistivity $5-10 \Omega$-cm) were used as substrates for carbon deposition; substrates were cleaned with piranha solution $(3: 1$ $\mathrm{H}_{2} \mathrm{SO}_{4}: \mathrm{H}_{2} \mathrm{O}_{2} ;$ CAUTION: Piranha solution is a strong oxidant which may react explosively with organic solvents - always use in a fumehood) before rinsing with Millipore water and drying under Ar. Glassy carbon (GC) discs (HTW Sigradur ${ }^{\circledR}$ radius $0.25 \pm 0.05 \mathrm{~cm}$ ) were polished with progressively finer grades of alumina slurry (Buehler). Discs were first polished using 1200 grit sandpaper and $1 \mu \mathrm{m}$ slurry. After rinsing with copious Millipore water the discs were polished on nylon paper (Buehler) using $1 \mu \mathrm{m}$ slurry, sonicated for $20 \mathrm{~min}$ in Millipore water, then polished on nylon paper using $0.3 \mu \mathrm{m}$ slurry. Polishing MicroCloths ${ }^{\circledR}$ (Buehler) with $0.3 \mu \mathrm{m}$ slurry were used for the penultimate step before once again sonicating for $20 \mathrm{~min}$ in Millipore water. The final polishing step was $0.05 \mu \mathrm{m}$ slurry on a fresh microcloth before sonicating the polished discs in Millipore water for $20 \mathrm{~min}$. Clean discs were either used directly in electrochemical experiments or, in the case of a-C and a-C:N depositions, mounted in a custom-made Teflon ${ }^{\circledR}$ holder and placed in the vacuum chamber for coating via magnetron sputtering.

Deposition of carbon electrode materials. Thin film electrodes of amorphous carbon (a-C) and nitrogenated amorphous carbon $(\mathrm{a}-\mathrm{C}: \mathrm{N})$ were deposited via DC magnetron sputtering in a chamber (Torr International Inc.) with a base pressure $\leq 2 \times 10^{-6} \mathrm{mbar}$ and a deposition pressure in the range $2-7 \times 10^{-3}$ mbar. Films with varying Nitrogen percentages were prepared by introducing a nitrogen (N4.5, BOC) and argon (N4.8, BOC) gas mixture into the sputtering chamber using two mass flow controllers (Brooks Instruments). The total gas flow rate was kept at $50 \mathrm{ml} \mathrm{min}{ }^{-1}$, while the mixing ratio was varied to alter the nitrogen content in the films; 
deposition time was kept constant at 40 min for all samples, resulting in smooth films (see Supporting Information) as previously reported. ${ }^{46}$

Characterization. Ellipsometry measurements were taken using an alpha-SETM Ellipsometer (J.A. Woolam Co.). The films were deposited on Si wafers and measured at $65^{\circ}, 70^{\circ}$ and $75^{\circ}$ incidence; data were fitted using a 3-layer model which takes into account the substrate, the a$\mathrm{C} / \mathrm{a}-\mathrm{C}: \mathrm{N}$ layer and the air phase, as previously reported ${ }^{47}$ Electrochemical measurements were carried out using a Metrohm Autolab AUT50324 potentiostat with a Frequency Response Analyser (FRA) module using a 3-electrode setup. A static disc holder (Pine Instruments) enclosing the a-C/a-C:N sputtered GC disc was used as working electrode (WE, see Supporting Information); a Hydroflex ${ }^{\circledR}$ hydrogen electrode (Gaskatel) and a Pt wire were used as reference and counter electrodes, respectively. The electrochemical cell consisted of a beaker with a custom-made Teflon ${ }^{\circledR}$ cap. Prior to experiments the cell was cleaned with piranha followed by rinsing 3 times with Millipore water. Cyclic voltammograms (CVs) in aqueous solutions of 1 $\mathrm{mM} \mathrm{Ru}\left(\mathrm{NH}_{3}\right)_{6} \mathrm{Cl}_{3} / \mathrm{Ru}\left(\mathrm{NH}_{3}\right)_{6} \mathrm{Cl}_{2}$ or $1 \mathrm{mM}$ Ferrocyanide in deaerated $0.1 \mathrm{M} \mathrm{KCl}$ at $25^{\circ} \mathrm{C}$ were obtained by scanning $\pm 0.3 \mathrm{~V}$ around the Formal Potential, $\mathrm{E}^{0}$ ' at a scan rate of $50 \mathrm{mV} / \mathrm{s}$; all voltammograms were taken with iR compensation using NOVA software. EIS spectra were obtained at $\mathrm{E}^{0}$, for both redox couples using 100 scans in the frequency range from $100 \mathrm{kHz}$ to $0.1 \mathrm{~Hz}$ using an AC amplitude of $8 \mathrm{mV}$. The resulting spectra were fitted with equivalent circuit models using commercial software (ZView). The geometric area of each disc was determined using calipers and verified via cyclic voltammetry experiments at various scan rates using the Randles-Sevcik equation (See Supplementary Information).

In the case of a-C films, X-ray photoelectron spectroscopy (XPS) characterization was performed at $1 \times 10^{-10}$ mbar base pressure in an ultrahigh vacuum system (Omicron). The X-ray 
source was a monochromatized Al Ka source $(1486.6 \mathrm{eV})$. Spectra were recorded at $45^{\circ}$ takeoff angle with an analyzer resolution of $0.5 \mathrm{eV}$. In the case of a-C:N films XPS characterization was performed on a VG Scientific ESCAlab Mk II system $\left(<2 \times 10^{-8}\right.$ mbar $)$, using Al K $\alpha$ X-rays (1486.6 eV); core-level spectra were collected with analyzer pass energy of $20 \mathrm{eV}$. Charge compensation, where applicable, was achieved using an electron flood gun and the binding energy scale was referenced to the C 1s core-level at $284.8 \mathrm{eV}$. Spectra were baseline corrected using a Shirley background and fitted with Voigt functions using commercial software (CasaXPS); atomic percent compositions were determined by calculating peak area ratios after correction by relative sensitivity factors $(\mathrm{C} 1 \mathrm{~s}=1.0, \mathrm{~N} 1 \mathrm{~s}=1.8, \mathrm{O} 1 \mathrm{~s}=2.93)$.

\section{Results and Discussion}

Nitrogen-incorporated amorphous carbon $(\mathrm{a}-\mathrm{C}: \mathrm{N})$ films were synthesized with different levels of nitrogen incorporation by varying the $\mathrm{N}_{2} /$ Ar ratio of the deposition gas; films are denoted as a$\mathrm{C}: \mathrm{N}-\mathrm{X} \%$ where $\mathrm{X}$ is the percentage of $\mathrm{N}_{2}$ out of a total flux of $50 \mathrm{sccm} \mathrm{N}_{2} /$ Ar. XPS survey scans of all a-C:N films show characteristic $\mathrm{C} 1 \mathrm{~s}, \mathrm{O} 1 \mathrm{~s}$ and $\mathrm{N} 1 \mathrm{~s}$ peaks at 284, 532 and $400 \mathrm{eV}$, respectively. In the absence of $\mathrm{N}_{2}$ in the deposition gas, non-nitrogenated amorphous carbon (aC) was prepared, as confirmed by the absence of $\mathrm{N} 1 \mathrm{~s}$ peaks in the survey spectra and by the shape of the C 1s envelope (Supplementary Information). Figure 1a and Table 1 show the changes in $\mathrm{N} / \mathrm{C} \%$ determined via XPS, observed when changing the $\mathrm{N}_{2} \%$ composition in the deposition gas. The plot suggests the presence of two different regimes of nitrogen incorporation. For low $\mathrm{N}_{2}$ content in the deposition gas $\left(\mathrm{N}_{2}<15 \%\right)$ nitrogen atoms are incorporated rapidly into the carbon material, however the rate of incorporation slows considerably for higher $\mathrm{N}_{2} \%$, in agreement with previous reports by other groups. ${ }^{48-50}$ The elevated $\mathrm{N} / \mathrm{C} \%$ values obtained in the 

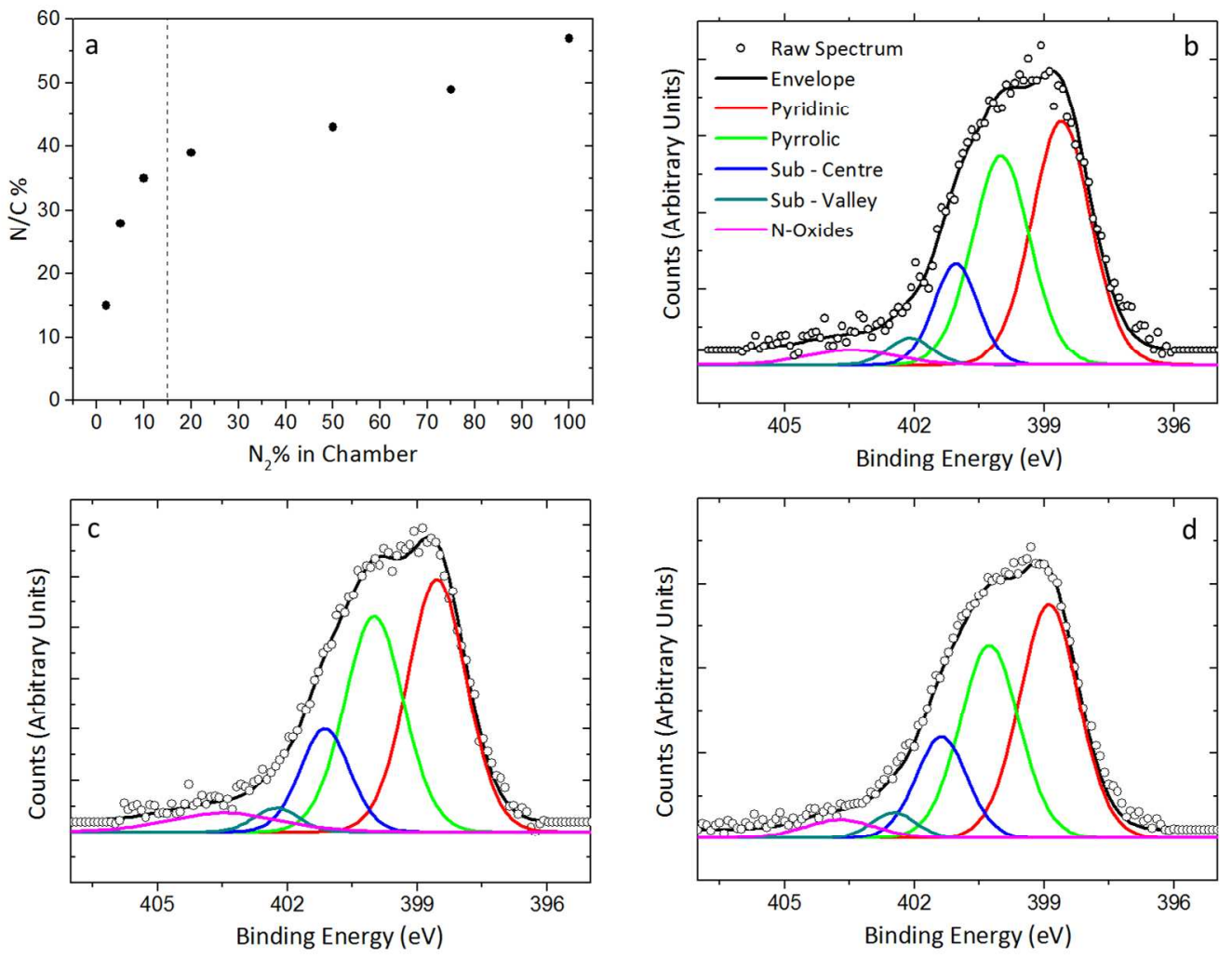

Figure 1. (a) $\mathrm{N} / \mathrm{C} \%$ versus $\mathrm{N}_{2} \%$ in the deposition gas. The dotted line delineates the two regimes of nitrogen incorporation. (b), (c), (d) Deconvoluted N 1s XPS spectra for a-C:N-2\% (b), a-C:N-5\% (c) and a-C:N-10\% (d). Raw spectra are shown after Shirley background substraction and offset for clarity

slow deposition regime $\left(\mathrm{N}_{2}>15 \%\right)$, suggest that films deposited under such conditions contain $\mathrm{N}-\mathrm{N}$ bonds and/or incorporate nitrogen gas within their structure. ${ }^{50-52}$

Figures $1 \mathrm{~b}-\mathrm{d}$ show the $\mathrm{N} 1 \mathrm{~s}$ spectra of a-C:N-2\%, 5\% and 10\%, respectively; similar $\mathrm{N} 1 \mathrm{~s}$ envelopes were obtained for a-C:N films deposited with $\mathrm{N}_{2}>10 \%$ (Supporting Information). The broad peak envelope indicates the presence of multiple types of $\mathrm{N}$-sites. The $\mathrm{N}$ 1s peaks were fitted using five contributions assigned to pyridinic-N (398.2 - 398.8 eV), pyrrolic-N (400 - $400.6 \mathrm{eV})$, substitutional-N $(400.8-402.6 \mathrm{eV})$ and $\mathrm{N}-\mathrm{O} / \mathrm{N}-\mathrm{N}(403-406 \mathrm{eV})$. The 
substitutional-N contribution was further separated into contributions from center- (400.8 $401.5 \mathrm{eV})$ and valley-type (402.1 - 402.8) N-sites. ${ }^{52,53}$ As noted by several authors, contributions above $403 \mathrm{eV}$ may also possibly be attributed to the presence of $\pi-\pi^{*}$ satellites; ${ }^{29,54}$. These satellites may contribute to our spectra however they would be convoluted with $\mathrm{N}-\mathrm{O}$ and $\mathrm{N}-\mathrm{N}$ contributions. Pyridinic-N and pyrrolic-N sites were found to dominate the $\mathrm{N}$ 1s spectra; the relative contribution of each type of $\mathrm{N}$-site to the total surface nitrogen content is reported in the Supporting Information. The C 1s spectra obtained for the same films also show an increasingly broad envelope with increasing nitrogen content in agreement with the presence of a range of $\mathrm{C}-\mathrm{N}$ functional groups contributions (Supporting Information). However, the strong spectral overlap observed above $285 \mathrm{eV}$ prevents unambiguous fitting of individual contributions to the $\mathrm{C} 1 \mathrm{~s}$ peak. ${ }^{29}$

Table 1. Surface composition of a-C and a-C:N-X\% samples obtained from XPS spectra.

\begin{tabular}{lcccccc} 
& & & \multicolumn{5}{c}{$\mathbf{N}_{\text {component }} / \mathbf{C} \%$} \\
\cline { 5 - 7 } $\mathbf{N}_{\mathbf{2}}$ & $\mathbf{N} / \mathbf{C}$ & $\mathbf{O} / \mathbf{C}$ & $\begin{array}{c}\mathbf{N}_{\text {pyri }} \\
\mathbf{g a s}\end{array}$ & $\begin{array}{c}\mathbf{N}_{\text {pyrr }} \\
\mathbf{\%}\end{array}$ & $\begin{array}{c}\mathbf{N}_{\text {sub }} \\
\mathbf{\%}\end{array}$ & $\begin{array}{c}\mathbf{N}_{\mathbf{o x}} \\
\mathbf{\%}\end{array}$ \\
\hline $\mathbf{0 \%}$ & 0 & 8 & 0 & 0 & 0 & 0 \\
\hline $\mathbf{2 \%}$ & 15 & 10 & 6 & 5 & 3 & 1 \\
$\mathbf{5 \%}$ & 28 & 8 & 12 & 10 & 5 & 2 \\
$\mathbf{1 0 \%}$ & 35 & 5 & 16 & 12 & 6 & 1 \\
$\mathbf{2 0 \%}$ & 39 & 6 & 17 & 13 & 8 & 1 \\
$\mathbf{5 0 \%}$ & 43 & 5 & 18 & 13 & 10 & 2 \\
$\mathbf{7 5 \%}$ & 49 & 10 & 21 & 15 & 11 & 2 \\
$\mathbf{1 0 0 \%}$ & 57 & 9 & 24 & 18 & 12 & 3 \\
\hline
\end{tabular}


a

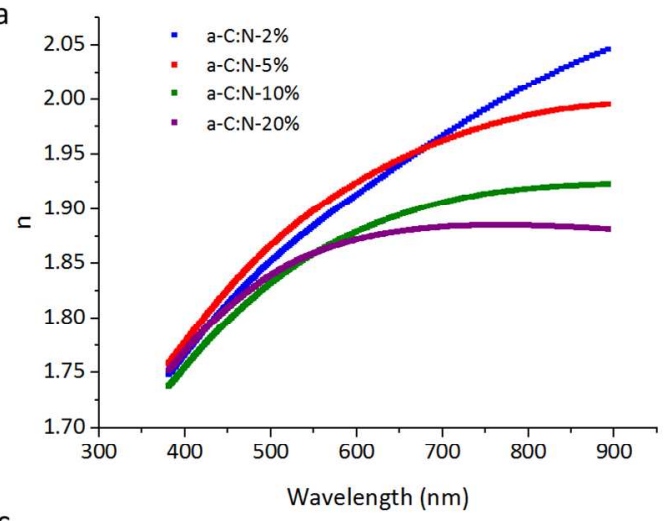

c

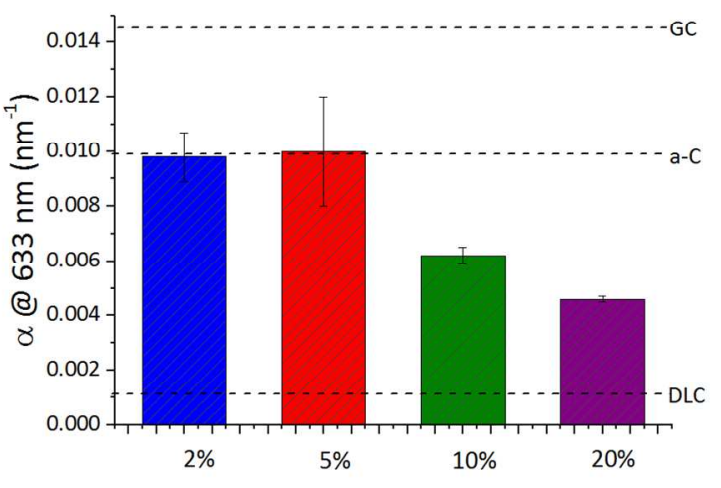

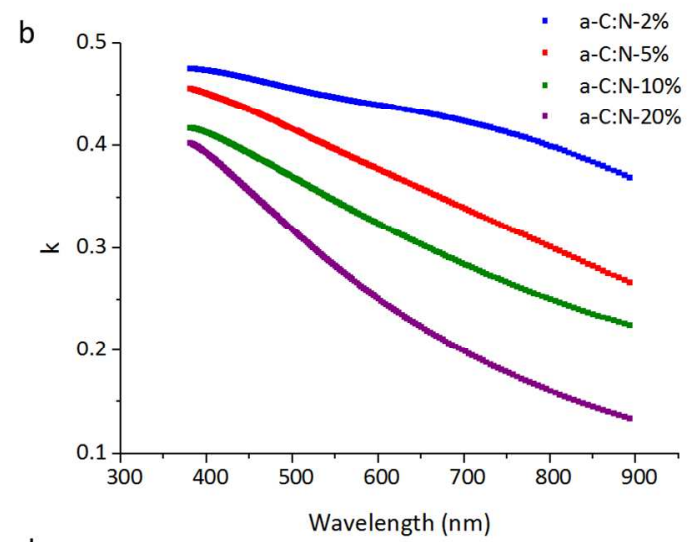

d

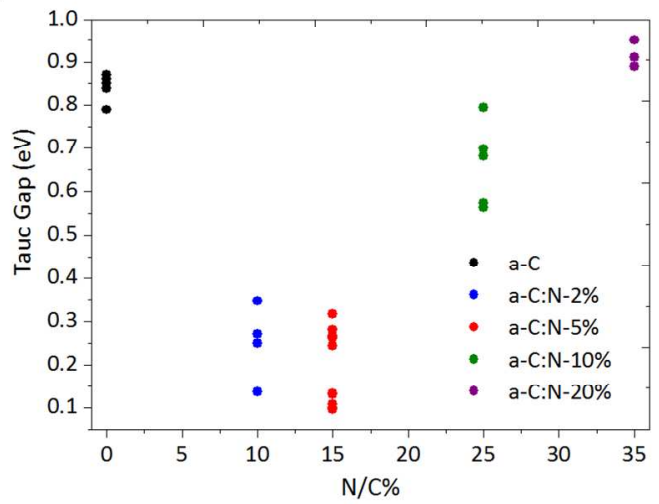

Figure 2. (a) Plots of index of refraction (n) derived from SE measurements of a-C:N-2-20\% versus wavelength $(\mathrm{nm})$. (b) Plots of extinction coefficient $(\mathrm{k})$ versus wavelength for a-C:N-220\%. (c) Bar plot of the absorption coefficient, $\alpha @ 633 \mathrm{~nm}$ for a-C:N-2-20\%. Dotted lines refer to a-C films prepared by our group, reported GC absorptivity ${ }^{55}$ and $\mathrm{sp}^{3}$-rich DLC films characterized by Mednikarov et al. ${ }^{56}$ (d) Cluster plot of Tauc gaps of a-C:N-2-20\% versus $\mathrm{N} / \mathrm{C} \%$. Tauc gaps of a-C films (with $\mathrm{N} / \mathrm{C} \%=0$ ) prepared and previously characterized by the group are also presented for comparison.

The bulk optoelectronic properties of a-C:N materials were investigated via spectroscopic ellipsometry. Figures $2 \mathrm{a}$ and $2 \mathrm{~b}$ show representative plots of the optical constants, $n$ and $k$ for aC:N-2-20\% vs. wavelength in the 400-900 $\mathrm{nm}$ range. The real part of the refractive index, $n$, was found to be similar for all samples whilst the trend in the imaginary component, $k$, indicates that the absorptivity of the films in the visible range decreases with increasing levels of $\mathrm{N}$ incorporation. Figure $2 \mathrm{c}$ shows a comparison of the absorption coefficient $\alpha$ at $633 \mathrm{~nm}$, calculated as $\alpha=\frac{4 \pi k}{\lambda}$, for a-C:N-2-20\%; values obtained for non-nitrogenated films and literature 
values for $\mathrm{GC}^{55}$ and diamond-like carbon (DLC) ${ }^{56}$ are also reported as a comparison. Low levels of nitrogen incorporation (2-5\%) produce films with absorptivity similar to or slightly greater than that of un-doped a-C, whilst for higher levels of nitrogenation (10-20\%) the absorptivity decreases significantly. Absorption coefficients as a function of photon energy were used to calculate Tauc plots from which the optical Tauc gap values $\left(\mathrm{E}_{\mathrm{T}}\right)$ were obtained, as shown in the Supporting Information. Figure $2 \mathrm{~d}$ reports $\mathrm{E}_{\mathrm{T}}$ values as a function of $\mathrm{N} / \mathrm{C} \%$ content in the carbon material; the results show that a-C:N films prepared with low levels $(2-5 \%)$ of $\mathrm{N}$-incorporation have the narrowest optical gaps whilst at higher nitrogen incorporation (a-C:N-10-20\%) the optical gap increases. This is consistent with previous reports indicating that low levels of Nincorporation raise the Fermi level of the material and lower its optical band gap ${ }^{22,57}$ relative to non-nitrogenated carbons. Based on our results, this effect is observed only for low levels of nitrogen incorporation while carbons with $\mathrm{N} / \mathrm{C} \%>15 \%$ display greater semiconductive character.

Above a-C:N-20\% the optical properties of the resulting films significantly depart from those obtained at lower $\mathrm{N}_{2} \%$ values. Figure 3 shows plots of the imaginary component of the refractive index versus wavelength for a-C:N samples deposited at high $\mathrm{N}_{2} \%$ in the deposition mixture. For these films, the $k$ values do not vary smoothly and monotonously as expected of amorphous solids, but display broad peak-like features. These broad peaks suggest the presence of disordered conjugated clusters in these a-C:N films: the formation of relatively small, poorlyconnected graphitic clusters with localized electron density is expected to result in "moleculelike" optical transitions such as those observed for a-C:N-50-100\%. Our results are also consistent with work by Rodil et al., who proposed that the increase in $\mathrm{E}_{\mathrm{T}}$ values usually observed with increasing $\mathrm{N} / \mathrm{C} \%$ content can be attributed to increased localization of $\pi$ electrons. $^{58}$ 


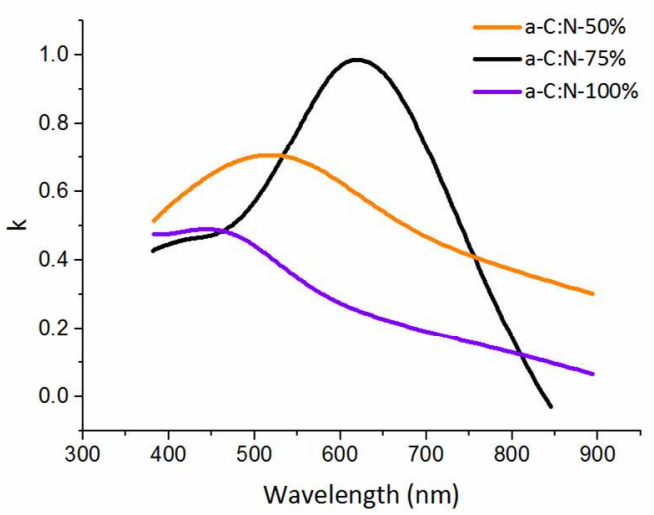

Figure 3. Extinction coefficient $(k)$ versus wavelength for a-C:N-50\%, 75\% and 100\% derived from ellipsometry measurements.

\section{Electrochemical Characterization of a-C and a-C:N Films}

Cyclic voltammetry and electrochemical impedance measurements were carried out to study the effects of nitrogen incorporation on the electron transfer properties of a-C materials. The $\mathrm{Ru}\left(\mathrm{NH}_{3}\right)_{6}{ }^{+2 /+3}$ redox couple was first chosen as an electrochemical probe. This complex is an 'outer-sphere' redox species which is relatively insensitive to surface chemistry, ${ }^{59}$ but whose rate of charge-transfer is controlled by the electronic properties of the electrode, such as Fermi level position $\left(\mathrm{E}_{\mathrm{F}}\right)$, and density of states (DOS) near $\mathrm{E}_{\mathrm{F}}$.

Figure 4 shows $\mathrm{CV}$ s obtained for a-C:N-X\% electrodes in $1 \mathrm{mM} \mathrm{Ru}\left(\mathrm{NH}_{3}\right)_{6}^{+2 /+3}$ with $0.1 \mathrm{M} \mathrm{KCl}$. The figure indicates that low levels of nitrogen incorporation result in electrodes with the smallest peak-to-peak separation $\left(\Delta \mathrm{E}_{\mathrm{p}}\right)$ and the highest capacitance-corrected peak current density values $\left(\sim 3 \times 10^{-4} \mathrm{~A} \mathrm{~cm}^{-2}\right) . \Delta \mathrm{E}_{\mathrm{p}}$ values of $70-80 \mathrm{mV}$ obtained for a-C:N-2-5\% at $50 \mathrm{mV}$ $\mathrm{s}^{-1}$ (Table 2) are close to the reversible limit of $59 \mathrm{mV}$ for a one-electron process, indicating that electron transfer is fast for low levels of nitrogenation. Since each experiment was carried out with the same concentration of $\mathrm{Ru}\left(\mathrm{NH}_{3}\right)_{6}{ }^{+2 /+3}$, differences in peak current density for different 


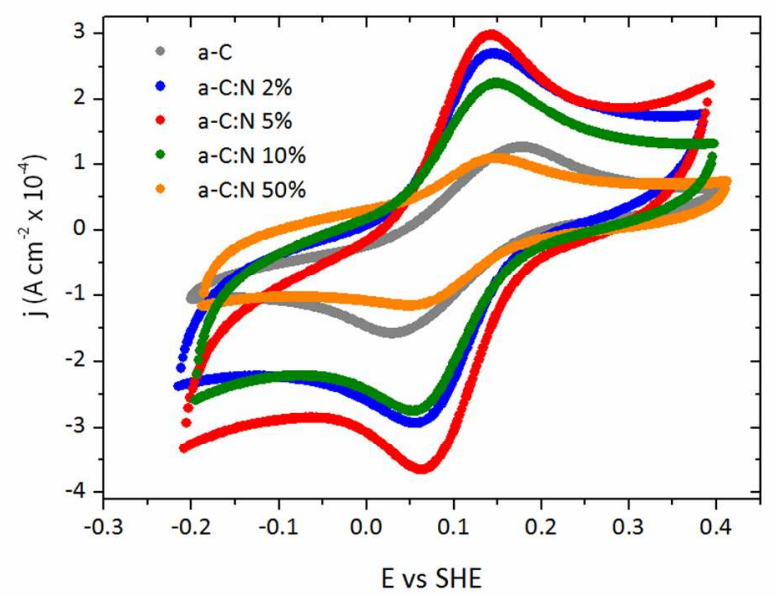

Figure 4. Cyclic Voltammograms of selected a-C: $\mathrm{N}$ films in solutions of $1 \mathrm{mM} \mathrm{Ru}\left(\mathrm{NH}_{3}\right)_{6}^{+2 /+3}$ in $0.1 \mathrm{M} \mathrm{KCl}$.

Table 2. Peak Current Density ratios and Peak Potential Separations for nitrogenated and non-

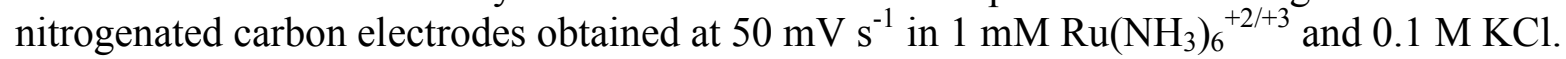
Errors indicate $95 \%$ confidence interval.

\begin{tabular}{lcc}
\hline Sample & $\mathbf{J}_{\mathbf{p c}} / \mathbf{J}_{\mathbf{p a}}$ & $\Delta \mathbf{E}_{\mathbf{p}}(\mathbf{V})$ \\
\hline $\mathbf{a}-\mathbf{C}$ & $0.9 \pm 0.2$ & $0.15 \pm 0.02$ \\
$\mathbf{a - C : N - 2 \%}$ & $0.9 \pm 0.1$ & $0.08 \pm 0.01$ \\
$\mathbf{a - C : N - 5 \%}$ & $0.91 \pm 0.06$ & $0.074 \pm 0.007$ \\
$\mathbf{a - C : N - 1 0 \%}$ & $0.93 \pm 0.09$ & $0.09 \pm 0.01$ \\
$\mathbf{a - C : N - 5 0 \%}$ & $1.0 \pm 0.1$ & $0.095 \pm 0.002$ \\
\hline
\end{tabular}

films may possibly be explained by changes in the electroactive area of the sputtered electrodes; this is also consistent with the observed drop in the capacitive contribution to the current for a$\mathrm{C}: \mathrm{N}-50 \%$. The decrease in peak current density occurs in the absence of a significant change in $\Delta \mathrm{E}_{\mathrm{p}}$. This suggests that the electrodes at high $\mathrm{N} / \mathrm{C}$ content are better described as heterogeneous partially-blocked electrodes, which have been shown to display similar behaviour in their voltammetric response, depending on microdomain size and distribution. ${ }^{60}$ 
Figure 5. (a) High frequency Nyquist plots for a-C and selected examples of a-C:N-X\% in 1 $\mathrm{mM} \mathrm{Ru}\left(\mathrm{NH}_{3}\right)_{6}{ }^{+2 / 3}$ with $0.1 \mathrm{M} \mathrm{KCl}$ (b) Plot of $\mathrm{R}_{\mathrm{CT}}$ versus $\mathrm{N} / \mathrm{C} \%$ for the Ruthenium redox couple. The legends in both (a) and (b) refer to the $\mathrm{N}_{2} / \mathrm{Ar} \%$ in the deposition gas during sputtering.

In all cases the ratio of cathodic to anodic peak current densities $\left(\mathrm{J}_{\mathrm{p}, \mathrm{c}} / \mathrm{J}_{\mathrm{p}, \mathrm{a}}\right)$ is $>0.9$ which is close to the theoretical value of 1 for an electrochemically reversible process. Non-nitrogenated a-C yielded a significantly larger $\Delta \mathrm{E}$ of $\sim 150 \mathrm{mV}$ (Table 2) therefore indicating that low levels of nitrogenation result in an enhancement of the electron transfer rate. However, as the $\mathrm{N}_{2} \%$ increases in the deposition mixture, this trend reverses and for a-C:N-50\%, the peak separation increases to almost $100 \mathrm{mV}$. This increase is accompanied by a decrease in peak current density to a value comparable to that of a-C. Finally, a-C:N-X\% films with $\mathrm{X}=75,100$ were found to be too resistive for electrochemical measurements.

In order to quantitatively compare the electron-transfer properties of our films, Electrochemical 
Impedance Spectroscopy (EIS) was used to determine the resistance to charge transfer $\left(\mathrm{R}_{\mathrm{CT}}\right)$ at the formal potential $\left(\mathrm{E}^{0}\right)$ of the Ruthenium redox couple. Representative Nyquist plots for a-C:N electrodes in $1 \mathrm{mM} \mathrm{Ru}\left(\mathrm{NH}_{3}\right)_{6}{ }^{+2 /+3}$ with $0.1 \mathrm{M} \mathrm{KCl}$ are shown in Figure 5a together with the plot obtained for a-C under the same conditions (see also Supporting Information). Typical features of a mixed kinetic-diffusion process are evident in all complex spectra: a semicircle at high frequency $\left(10^{5}-10^{3} \mathrm{~Hz}\right)$ suggests the presence of an impedance to charge-transfer $\left(\mathrm{R}_{\mathrm{CT}}\right)$ in parallel with a capacitive contribution, while at low frequencies $\left(10^{3}-10^{-1} \mathrm{~Hz}\right)$ a linear behaviour with $\sim 45^{\circ}$ slope indicates that the impedance is dominated by mass transport limited diffusion. EIS spectra for a-C and a-C:N-2-50\% in $\mathrm{Ru}\left(\mathrm{NH}_{3}\right)_{6}{ }^{+2 /+3}$ were fitted using a Randles circuit (Supporting Information); the resulting $\mathrm{R}_{\mathrm{CT}}$ values are plotted vs. N/C\% content in Figure 5b; all parameters derived from the fitting procedure and calculated heterogeneous rate constants are reported in Supporting Information. Nitrogenated electrodes a-C:N-2-5\% yielded lower $\mathrm{R}_{\mathrm{CT}}$ values than non-nitrogenated a-C; the values for a-C:N-10\% are comparable to those of a-C, whereas those for a-C:N-20\% or higher increase progressively. This trend in $\mathrm{R}_{\mathrm{CT}}$ values agrees with $\Delta \mathrm{E}$ and peak-current density values obtained from $\mathrm{CV}$ measurements, and suggest that small nitrogen concentrations lead to an enhancement of charge transfer rates, whereas high levels of nitrogen incorporation negatively affect electrochemical performance. Interestingly, $\mathrm{R}_{\mathrm{CT}}$ values closely parallel $\mathrm{E}_{\mathrm{T}}$ vs. $\mathrm{N} / \mathrm{C} \%$ trends determined via ellipsometry; in fact, $\mathrm{R}_{\mathrm{CT}}$ and $\mathrm{E}_{\mathrm{T}}$ appear to be positively correlated ( $\mathrm{R}=0.9458)$ (Supporting Information). a-C:N electrodes with the lowest $\Delta \mathrm{E}_{\mathrm{p}}$ values and largest peak current densities are the a-C:N films with the greatest metallic character, based on $\mathrm{E}_{\mathrm{T}}$ determinations. Furthermore, the collapse in peak current density for a-C:N-50\% correlates well with the appearance of broad absorption peaks in the imaginary refractive index which are suggestive of greater electronic localization. For both regimes of N- 


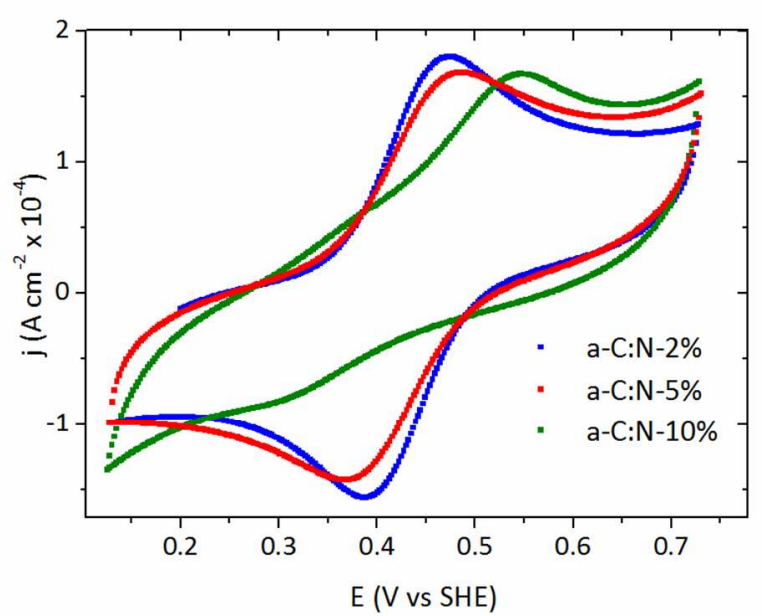

Figure 6. Cyclic voltammograms of $1 \mathrm{mM} \mathrm{Fe}(\mathrm{CN})_{6}^{-4 /-3}$ in $0.1 \mathrm{M} \mathrm{KCl}$, obtained at $50 \mathrm{mV} \mathrm{s}^{-1}$ for a-C and a-C:N-2-10\%.

Table 3. Peak current density ratio $\left(\mathrm{J}_{\mathrm{p}, \mathrm{c}} / \mathrm{J}_{\mathrm{p}, \mathrm{a}}\right)$ and $\Delta \mathrm{E}_{\mathrm{p}}$ values for a-C and a-C:N-2-10\% obtained in $1 \mathrm{mM} \mathrm{Fe}(\mathrm{CN})_{6}^{-4 /-3}$ with $0.1 \mathrm{M} \mathrm{KCl}$ at $50 \mathrm{mV} \mathrm{s}^{-1}$

\begin{tabular}{llc}
\hline Sample & \multicolumn{1}{c}{$\mathbf{J}_{\mathbf{p c}} / \mathbf{J}_{\mathbf{p a}}$} & $\Delta \mathbf{E}_{\mathbf{p}}(\mathbf{V})$ \\
\hline $\mathbf{a}-\mathbf{C}$ & $0.95 \pm 0.05$ & $0.08 \pm 0.03$ \\
$\mathbf{a}-\mathbf{C}: \mathbf{N}-\mathbf{2 \%}$ & $0.8 \pm 0.1$ & $0.08 \pm 0.02$ \\
$\mathbf{a - C}: \mathbf{N - 5 \%}$ & $0.9 \pm 0.1$ & $0.1 \pm 0.05$ \\
$\mathbf{a - C}: \mathbf{N}-\mathbf{1 0} \%$ & 0 & - \\
\hline
\end{tabular}

incorporation there is therefore a strong correlation between the bulk optoelectronic properties and electron transfer properties of the films using the $\mathrm{Ru}\left(\mathrm{NH}_{3}\right)_{6}{ }^{+2 /+3}$ redox probe.

\section{Electrochemical Characterization using $\mathrm{Fe}(\mathrm{CN})_{6}^{-4 /-3}$}

Redox couples such as $\mathrm{Ru}\left(\mathrm{NH}_{3}\right)_{6}{ }^{+2 /+3}$ are in the minority with regards to their relative insensitivity to surface termination in electron transfer processes. In order to understand the effect of nitrogen incorporation on the surface chemistry of carbon electrodes we carried out CV and EIS measurements of a-C and a-C:N-X\% in aqueous solutions of $\mathrm{Fe}(\mathrm{CN})_{6}^{-4 /-3}$, a redox probe 


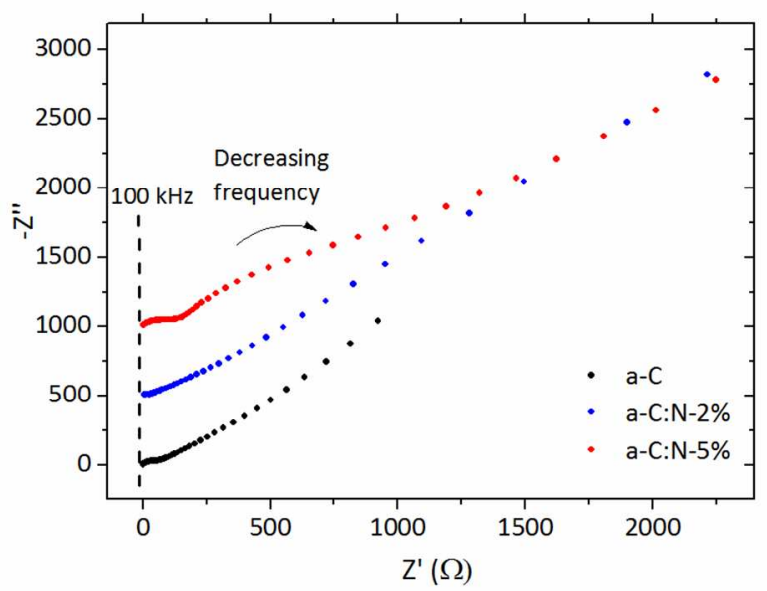

Figure 7. Nyquist plots of $1 \mathrm{mM} \mathrm{Fe}(\mathrm{CN})_{6}^{-4 /-3}$ in $0.1 \mathrm{M} \mathrm{KCl}$ obtained for a-C and a-C:N-2-5\%.

that is known to be sensitive to surface functionalities (e.g. passive layers and charged groups). ${ }^{59}$

Figure 6 shows CVs of carbon electrodes in $1 \mathrm{mM} \mathrm{Fe}(\mathrm{CN})_{6}{ }^{-4}$ and $0.1 \mathrm{M} \mathrm{KCl}$ for a-C and a-C:N$2-10 \%$. As shown in the figure, the $\Delta \mathrm{E}_{\mathrm{p}}$ for a-C and a-C:N-2\% is approximately $80 \mathrm{mV}$, whilst $\Delta \mathrm{E}_{\mathrm{p}}$ for a-C:N-5\% is slightly higher at $100 \mathrm{mV}$. The $\mathrm{J}_{\mathrm{p}, \mathrm{c}} / \mathrm{J}_{\mathrm{p}, \mathrm{a}}$ (Table 3) is close to 1 for all of these films, indicating that the redox process is reversible for both a-C and a-C:N-2-5\% in the case of the $\mathrm{Fe}(\mathrm{CN})_{6}^{-4 /-3}$ couple. In the case of a-C:N-10\% the anodic peak, $\mathrm{E}_{\mathrm{p}, \mathrm{a}}$ is shifted more than 100 $\mathrm{mV}$ in the positive direction and the cathodic peak $\mathrm{E}_{\mathrm{p}, \mathrm{c}}$ is greatly reduced. This indicates that charge transfer is irreversible for $\mathrm{Fe}(\mathrm{CN})_{6}^{-4 /-3}$ on a-C:N-10\%.

Nyquist plots for a-C and a-C:N films in $1 \mathrm{mM} \mathrm{Fe}(\mathrm{CN})_{6}^{-4}$ in $0.1 \mathrm{M} \mathrm{KCl}$ are shown in Figure 7. Similar to the results for the $\mathrm{Ru}\left(\mathrm{NH}_{3}\right)_{6}{ }^{+2 /+3}$ couple, evidence of a mixed kinetic-diffusion controlled electron transfer process can be seen for a-C and a-C:N-2-5\%. Due to the irreversibility of a-C:N-10\% determined via CV studies, EIS experiments were not attempted on this substrate. For both a-C and a-C:N-2\% the semicircle in the high frequency $\left(10^{5}-10^{3} \mathrm{~Hz}\right)$ region indicates that the impedance to charge transfer is low for both a-C and a-C:N-2\% with 
similar magnitudes of $\mathrm{R}_{\mathrm{CT}}$. The linear behaviour of the plots in the low frequency region $\left(10^{3}-10^{-}\right.$ ${ }^{1} \mathrm{~Hz}$ ) of the figure indicates that ferrocyanide oxidation may proceed rapidly enough to be diffusion-rate limited on both surfaces. In the case of a-C:N-5\%, the broad semicircle in the region from $10^{2}$ to $1 \mathrm{~Hz}$ a-C:N-5\% plot corresponds to Randles behaviour with a larger contribution of $\mathrm{R}_{\mathrm{CT}}$ to the impedance. This is in agreement with $\mathrm{CV}$ data for a-C:N 5\%, which indicate that $\Delta \mathrm{E}_{\mathrm{p}}$ values for charge transfer to ferrocyanide are slightly larger in the case of a$\mathrm{C}: \mathrm{N} 5 \%$. The high-frequency region of the impedance plot for a-C:N-5\% indicates the appearance of a smaller RC component which is present even in the absence of any redox-active species (i.e. in supporting electrolyte, $0.1 \mathrm{M} \mathrm{KCl}$; Supporting Information). This contribution has previously been observed in the EIS of amorphous carbon materials, ${ }^{61,62}$ and might be attributed to defects likely to occur in non-crystalline materials, including nanoporosity and mid-gap or surface states. ${ }^{63-65}$

Both voltammetric and impedance experiments indicate that nitrogen-incorporation into amorphous carbon electrodes results in surfaces which are progressively less amenable to charge transfer to the $\mathrm{Fe}(\mathrm{CN})_{6}^{-4 /-3}$ redox couple. The increase in $\Delta \mathrm{E}_{\mathrm{p}}$ and $\mathrm{R}_{\mathrm{CT}}$ from a-C to a-C:N-5\% and the irreversibility of charge transfer to a-C:N-10\% contrasts with the results for $\left.\mathrm{Ru}_{(} \mathrm{NH}_{3}\right)_{6}{ }^{+2+3}$, which showed lower $\Delta \mathrm{E}_{\mathrm{p}}$ and $\mathrm{R}_{\mathrm{CT}}$ values following nitrogenation and quasi-reversible behaviour for all a-C:N films studied.

Given that the bulk optoelectronic properties of a-C:N-2-10\% are known to be more metallic in nature than undoped a-C, this contrasting behaviour is likely to be explained by surface effects on the kinetics of electron transfer. There is evidence that charge transfer to ferrocyanide is catalyzed by the supporting electrolyte, which facilitates the redox process via formation of cationic bridging complexes. ${ }^{66-69}$ The availability of specific surface sites is also known to be 
important in determining the rate of charge transfer of $\mathrm{Fe}(\mathrm{CN})_{6}^{-4 /-3}$ at carbon electrodes. ${ }^{70,71} \mathrm{~A}$ recent study by Compton and co-workers ${ }^{66}$ showed that ferrocyanide oxidation at graphite electrodes could be rendered almost entirely irreversible by pre-treating the carbon surface with organic solvents such as acetonitrile. Their study concluded that the inhibitory effects of the organic solvent were due to blocking of the active edge sites which in turn prevent the cation bridging required for electron transfer to occur. We propose that the incorporation of nitrogen moieties into the carbon matrix of our films may produce a similar inhibitory effect which is intrinsic to the surface. This result is significant as it underscores the fact that, while the incorporation of nitrogen into the carbon matrix may result in improved bulk electronic properties that typically enhance rates of charge transfer (lower $\mathrm{E}_{\mathrm{T}}$, greater metallic character), it also results in surface nitrogenation that significantly changes interfacial interactions with redox species. Whilst nitrogenation is often associated with improved catalytic properties, as is for instance the case in oxygen reduction, nitrogenation can also result in more sluggish kinetics and an overall inhibitory effect as in the case of charge transfer to the ferrocyanide complex.

\section{Conclusions}

We have prepared nitrogenated amorphous carbon films with varying N/C \% and characterized them using a combination of optical and electrochemical methods. Our results indicate that low levels of nitrogenation produce films with greater metallic character when compared to nonnitrogenated amorphous carbon. These films also display the fastest electron-transfer kinetics for the Ruthenium Hexaammine redox couple as measured by a combination of cyclic voltammetry and impedance spectroscopy. We have demonstrated that the resistance to electron transfer, $\mathrm{R}_{\mathrm{CT}}$, is strongly correlated to the Tauc gap, $\mathrm{E}_{\mathrm{T}}$, in what we believe is the first demonstration of a clear correlation between optoelectronic and electrochemical properties in nitrogenated carbon 
materials.

Highly nitrogenated amorphous carbon films display properties more consistent with localized and poorly-connected arrays of graphitic clusters rather than amorphous solids. These properties were observed both optically, through ellipsometric measurements, and electrochemically based on the inferior electron transfer properties of these materials relative to a-C: $\mathrm{N}$ films with lower levels of nitrogenation. An important implication of these results is that ellipsometry emerges as an effective method for the evaluation of defects in carbon electrodes that result from nitrogenation and that the defectiveness evidenced via ellipsometry is straightforwardly reflected in the electrochemical performance.

It is interesting to note the remarkable difference observed in trends of charge transfer rates

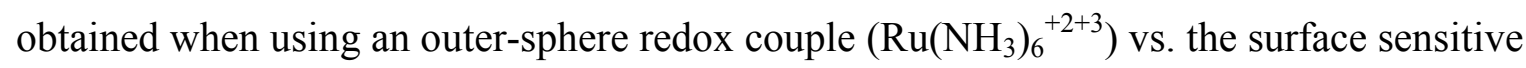
$\mathrm{Fe}(\mathrm{CN})_{6}^{-4 /-3}$ couple. The introduction of nitrogenated sites facilitates charge transfer in the case of the outer-sphere species, in agreement with an expected increase in charge carriers and metallic character that typically arises from nitrogen doping of carbon materials. The opposite trend is observed for the inner-sphere couple thus indicating that nitrogenation has a profound effect on the surface chemistry and that these effects might dominate the overall electrochemical response of the nitrogenated carbon. The combined effect of bulk optoelectronic changes and surface modifications that result from nitrogenation, strongly depends on the specific redox species in solution. Our results suggest that theoretical predictions of charge transfer rates for ruthenium hexamine based on bulk electronic structure are likely to be accurate at nitrogenated carbons. However, specific models that describe interfacial interactions are required to predict the behavior and trends of inner-sphere redox species at nitrogenated surfaces. Finally, this study offers clear evidence of the need for both outer and inner-sphere redox couples to understand the 
origin of changes in the overall electrochemical response arising from nitrogenation of carbon electrodes.

\section{Associated Content}

Pictures of the working electrode arrangement, supplemetary XPS results, Tauc plots, RandlesSevcik analysis, Bode plots, EIS fitting models and parameters, heterogeneous rate constant values and SEM images of a-C and a-C:N films. This material is available free of charge via the Internet at http://pubs.acs.org.

\section{Acknowledgement}

This publication has emanated from research conducted with the financial support of Science Foundation Ireland (SFI) Grant No. 13/CDA/2213. FZ acknowledges support from SFI Grant No. 12/IP/1273; JAB acknowledges support from the Irish Research Council through Grant No. GOIPG/2014/399; LET acknowledges support from SFI Grant No. 12/RC/2278. Use of the XPS instrument of I.V. Shvets and C. McGuinness was provided under SFI Equipment Infrastructure Funds.

\section{References}

(1) Robertson, J.; Davis, C. A. Nitrogen Doping of Tetrahedral Amorphous-Carbon. Diamond Relat. Mater. 1995, 4, 441-444.

(2) Properties of Amorphous Carbon; 1st ed.; Silva, S. R. P., Ed.; INSPEC, Inc. The Institution of Electrical Engineers: London, 2003.

(3) Yoo, K.; Miller, B.; Kalish, R.; Shi, X. Electrodes of Nitrogen-Incorporated Tetrahedral Amorphous Carbon a Novel Thin-Film Electrocatalytic Material with Diamond-Like Stability. Electrochem. Solid-State Lett. 1999, 2, 233-235.

(4) Kamata, T.; Kato, D.; Hirono, S.; Niwa, O. Structure and Electrochemical Performance of Nitrogen-Doped Carbon Film Formed by Electron Cyclotron Resonance Sputtering. Anal. Chem. 2013, 85, 9845-9851. 
(5) Yang, X.; Haubold, L.; DeVivo, G.; Swain, G. M. Electroanalytical Performance of Nitrogen-Containing Tetrahedral Amorphous Carbon Thin-Film Electrodes. Anal. Chem. 2012, $84,6240-6248$.

(6) Perini, L.; Durante, C.; Favaro, M.; Agnoli, S.; Granozzi, G.; Gennaro, A. Electrocatalysis at Palladium Nanoparticles: Effect of the Support Nitrogen Doping on the Catalytic Activation of Carbon-Halogen Bond. Appl. Catal., B 2014, 144, 300-307.

(7) Zhou, Y.; Neyerlin, K.; Olson, T. S.; Pylypenko, S.; Bult, J.; Dinh, H. N.; Gennett, T.; Shao, Z.; O'Hayre, R. Enhancement of Pt and Pt-Alloy Fuel Cell Catalyst Activity and Durability Via Nitrogen-Modified Carbon Supports. Energy Environ. Sci. 2010, 3, 1437-1446.

(8) Zeng, A.; Bilek, M. M. M.; McKenzie, D. R.; Lay, P. A.; La Fontaine, A.; Keast, V. J. Correlation between Film Structures and Potential Limits for Hydrogen and Oxygen Evolutions at a-C:N Film Electrochemical Electrodes. Carbon 2008, 46, 663-670.

(9) Brocenschi, R. F.; Rocha, R. C.; Li, L. L.; Swain, G. M. Comparative Electrochemical Response of Estrone at Glassy-Carbon, Nitrogen-Containing Tetrahedral Amorphous Carbon and Boron-Doped Diamond Thin-Film Electrodes. J. Electroanal. Chem. 2014, 712, 207-214.

(10) Sopchak, D.; Miller, B.; Kalish, R.; Avyigal, Y.; Shi, X. Dopamine and Ascorbate Analysis at Hydrodynamic Electrodes of Boron Doped Diamond and Nitrogen Incorporated Tetrahedral Amorphous Carbon. Electroanalysis 2002, 14, 473-478.

(11) Medeiros, R. A.; Matos, R.; Benchikh, A.; Saidani, B.; Debiemme-Chouvy, C.; Deslouis, C.; Rocha-Filho, R. C.; Fatibello-Filho, O. Amorphous Carbon Nitride as an Alternative Electrode Material in Electroanalysis: Simultaneous Determination of Dopamine and Ascorbic Acid. Anal. Chim. Acta 2013, 797, 30-39.

(12) Gai, P.; Zhang, H.; Zhang, Y.; Liu, W.; Zhu, G.; Zhang, X.; Chen, J. Simultaneous Electrochemical Detection of Ascorbic Acid, Dopamine and Uric Acid Based on Nitrogen Doped Porous Carbon Nanopolyhedra. J. Mater. Chem. B 2013, 1, 2742-2749.

(13) Fellinger, T.-P.; Hasché, F.; Strasser, P.; Antonietti, M. Mesoporous Nitrogen-Doped Carbon for the Electrocatalytic Synthesis of Hydrogen Peroxide. J. Am. Chem. Soc. 2012, 134, 4072-4075.

(14) Perazzolo, V.; Durante, C.; Pilot, R.; Paduano, A.; Zheng, J.; Rizzi, G. A.; Martucci, A.; Granozzi, G.; Gennaro, A. Nitrogen and Sulfur Doped Mesoporous Carbon as Metal-Free Electrocatalysts for the in Situ Production of Hydrogen Peroxide. Carbon 2015, 95, 949-963.

(15) Zhang, J.; Xia, Z.; Dai, L. Carbon-Based Electrocatalysts for Advanced Energy Conversion and Storage. $S c i$. $A d v$. 2015, 1 ,

(16) Mamtani, K.; Ozkan, U. S. Heteroatom-Doped Carbon Nanostructures as Oxygen Reduction Reaction Catalysts in Acidic Media: An Overview. Catal. Lett. 2015, 145, 436-450. 
(17) Ge, X.; Sumboja, A.; Wuu, D.; An, T.; Li, B.; Goh, F. W. T.; Hor, T. S. A.; Zong, Y.; Liu, Z. Oxygen Reduction in Alkaline Media: From Mechanisms to Recent Advances of Catalysts. ACS Catal. 2015, 5, 4643-4667.

(18) Wang, D.-W.; Su, D. Heterogeneous Nanocarbon Materials for Oxygen Reduction Reaction. Energy Environ. Sci. 2014, 7, 576-591.

(19) Ikeda, T.; Hou, Z.; Chai, G.-L.; Terakura, K. Possible Oxygen Reduction Reactions for Graphene Edges from First Principles. J. Phys. Chem. C 2014, 118, 17616-17625.

(20) Bao, X.; Nie, X.; von Deak, D.; Biddinger, E. J.; Luo, W.; Asthagiri, A.; Ozkan, U. S.; Hadad, C. M. A First-Principles Study of the Role of Quaternary-N Doping on the Oxygen Reduction Reaction Activity and Selectivity of Graphene Edge Sites. Top. Catal. 2013, 56, 16231633.

(21) Yasuda, S.; Yu, L.; Kim, J.; Murakoshi, K. Selective Nitrogen Doping in Graphene for Oxygen Reduction Reactions. Chem. Commun. 2013, 49, 9627-9629.

(22) Lai, L.; Potts, J. R.; Zhan, D.; Wang, L.; Poh, C. K.; Tang, C.; Gong, H.; Shen, Z.; Lin, J.; Ruoff, R. S. Exploration of the Active Center Structure of Nitrogen-Doped Graphene-Based Catalysts for Oxygen Reduction Reaction. Energy Environ. Sci. 2012, 5, 7936-7942.

(23) Guo, D.; Shibuya, R.; Akiba, C.; Saji, S.; Kondo, T.; Nakamura, J. Active Sites of NitrogenDoped Carbon Materials for Oxygen Reduction Reaction Clarified Using Model Catalysts.

Science 2016, 351, 361-365.

(24) Ikeda, T.; Boero, M.; Huang, S.-F.; Terakura, K.; Oshima, M.; Ozaki, J.-i. Carbon Alloy Catalysts: Active Sites for Oxygen Reduction Reaction. J. Phys. Chem. C 2008, 112, 1470614709 .

(25) Favaro, M.; Perini, L.; Agnoli, S.; Durante, C.; Granozzi, G.; Gennaro, A. Electrochemical Behavior of $\mathrm{N}$ and Ar Implanted Highly Oriented Pyrolytic Graphite Substrates and Activity toward Oxygen Reduction Reaction. Electrochim. Acta 2013, 88, 477-487.

(26) Shin, W. H.; Jeong, H. M.; Kim, B. G.; Kang, J. K.; Choi, J. W. Nitrogen-Doped Multiwall Carbon Nanotubes for Lithium Storage with Extremely High Capacity. Nano Lett. 2012, 12, 2283-2288.

(27) Morcos, I.; Yeager, E. Kinetic Studies of the Oxygen-Peroxide Couple on Pyrolytic Graphite. Electrochim. Acta 1970, 15, 953-975.

(28) Stamatin, S. N.; Hussainova, I.; Ivanov, R.; Colavita, P. E. Quantifying Graphitic Edge Exposure in Graphene-Based Materials and Its Role in Oxygen Reduction Reactions. ACS Catal. 2016, 6, 5215-5221.

(29) Maldonado, S.; Morin, S.; Stevenson, K. J. Structure, Composition, and Chemical Reactivity of Carbon Nanotubes by Selective Nitrogen Doping. Carbon 2006, 44, 1429-1437. 
(30) Deng, D.; Yu, L.; Pan, X.; Wang, S.; Chen, X.; Hu, P.; Sun, L.; Bao, X. Size Effect of Graphene on Electrocatalytic Activation of Oxygen. Chem. Commun. 2011, 47, 10016-10018.

(31) Jeon, I.-Y.; Choi, H.-J.; Jung, S.-M.; Seo, J.-M.; Kim, M.-J.; Dai, L.; Baek, J.-B. LargeScale Production of Edge-Selectively Functionalized Graphene Nanoplatelets Via Ball Milling and Their Use as Metal-Free Electrocatalysts for Oxygen Reduction Reaction. J. Am. Chem. Soc. 2013, 135, 1386-1393.

(32) Chen, P.; Fryling, M. A.; McCreery, R. L. Electron Transfer Kinetics at Modified Carbon Electrode Surfaces: The Role of Specific Surface Sites. Anal. Chem. 1995, 67, 3115-3122.

(33) Chen, L.-F.; Zhang, X.-D.; Liang, H.-W.; Kong, M.; Guan, Q.-F.; Chen, P.; Wu, Z.-Y.; Yu, S.-H. Synthesis of Nitrogen-Doped Porous Carbon Nanofibers as an Efficient Electrode Material for Supercapacitors. ACS Nano 2012, 6, 7092-7102.

(34) Nair, N.; Kim, W.-J.; Usrey, M. L.; Strano, M. S. A Structure-Reactivity Relationship for Single Walled Carbon Nanotubes Reacting with 4-Hydroxybenzene Diazonium Salt. J. Am. Chem. Soc. 2007, 129, 3946-3954.

(35) Sharma, R.; Nair, N.; Strano, M. S. Structure-Reactivity Relationships for Graphene Nanoribbons. J. Phys. Chem. C 2009, 113, 14771-14777.

(36) Strano, M. S.; Dyke, C. A.; Usrey, M. L.; Barone, P. W.; Allen, M. J.; Shan, H.; Kittrell, C.; Hauge, R. H.; Tour, J. M.; Smalley, R. E. Electronic Structure Control of Single-Walled Carbon Nanotube Functionalization. Science 2003, 301, 1519-1522.

(37) Heller, I.; Kong, J.; Williams, K. A.; Dekker, C.; Lemay, S. G. Electrochemistry at SingleWalled Carbon Nanotubes: The Role of Band Structure and Quantum Capacitance. J. Am. Chem. Soc. 2006, 128, 7353-7359.

(38) Zhong, J.-H.; Zhang, J.; Jin, X.; Liu, J.-Y.; Li, Q.; Li, M.-H.; Cai, W.; Wu, D.-Y.; Zhan, D.; Ren, B. Quantitative Correlation between Defect Density and Heterogeneous Electron Transfer Rate of Single Layer Graphene. J. Am. Chem. Soc. 2014, 136, 16609-16617.

(39) Batchelor-McAuley, C.; Laborda, E.; Henstridge, M. C.; Nissim, R.; Compton, R. G. Reply to Comments Contained in "Are the Reactions of Quinones on Graphite Adiabatic?", by N.B. Luque, W. Schmickler [Electrochim. Acta XX (2012) YYY]. Electrochim. Acta 2013, 88, 895898.

(40) Nissim, R.; Batchelor-McAuley, C.; Henstridge, M. C.; Compton, R. G. Electrode Kinetics at Carbon Electrodes and the Density of Electronic States. Chem. Commun. 2012, 48, 32943296.

(41) Unwin, P. R.; Güell, A. G.; Zhang, G. Nanoscale Electrochemistry of Sp2 Carbon Materials: From Graphite and Graphene to Carbon Nanotubes. Acc. Chem. Res. 2016, 49, 2041-2048. 
(42) Cachet, H.; Deslouis, C.; Chouiki, M.; Saidani, B.; Conway, N. M. J.; Godet, C. Electrochemistry of Nitrogen-Incorporated Hydrogenated Amorphous Carbon Films. $J$. Electrochem. Soc. 2002, 149, E233-E241.

(43) Zeng, A. P.; Bilek, M. M. M.; McKenzie, D. R.; Lay, P. A. Correlation of Film Structure and Molecular Oxygen Reduction at Nitrogen Doped Amorphous Carbon Thin Film Electrochemical Electrodes. Diamond Relat. Mater. 2009, 18, 1102-1108.

(44) Chen, J.; Wang, X.; Cui, X.; Yang, G.; Zheng, W. Amorphous Carbon Enriched with Pyridinic Nitrogen as an Efficient Metal-Free Electrocatalyst for Oxygen Reduction Reaction. Chem. Commun. 2014, 50, 557-559.

(45) Chen, J. Y.; Wang, X.; Cui, X. Q.; Yang, G. M.; Zheng, W. T. One-Step Synthesis of NDoped Amorphous Carbon at Relatively Low Temperature as Excellent Metal-Free Electrocatalyst for Oxygen Reduction. Catal. Commun. 2014, 46, 161-164.

(46) Cullen, R. J.; Jayasundara, D.; Soldi, L.; Cheng, J.; DuFaure, G.; Colavita, P. E. Spontaneous Grafting of Nitrophenyl Groups on Amorphous Carbon Thin Films: A StructureReactivity Investigation. Chem. Mater. 2012, 24, 1031-1040.

(47) Zen, F.; Angione, M. D.; Behan, J. A.; Cullen, R. J.; Duff, T.; Vasconcelos, J. M.; Scanlan, E. M.; Colavita, P. E. Modulation of Protein Fouling and Interfacial Properties at Carbon Surfaces Via Immobilization of Glycans Using Aryldiazonium Chemistry. Sci. Rep. 2016, 6, 24840 .

(48) Alibart, F.; Durand Drouhin, O.; Debiemme-Chouvy, C.; Benlahsen, M. Relationship between the Structure and the Optical and Electrical Properties of Reactively Sputtered Carbon Nitride Films. Solid State Commun. 2008, 145, 392-396.

(49) Alibart, F.; Lejeune, M.; Zellama, K.; Benlahsen, M. Effect of Nitrogen on the Optoelectronic Properties of a Highly $\mathrm{sp}^{2}$-Rich Amorphous Carbon Nitride Films. Diamond Relat. Mater. 2011, 20, 409-412.

(50) Hellgren, N.; Johansson, M. P.; Broitman, E.; Hultman, L.; Sundgren, J.-E. Role of Nitrogen in the Formation of Hard and Elastic $\mathrm{CN}_{\mathrm{x}}$ Thin Films by Reactive Magnetron Sputtering. Phys. Rev. B 1999, 59, 5162-5169.

(51) Hellgren, N.; Johansson, M. P.; Broitman, E.; Sandström, P.; Hultman, L.; Sundgren, J.-E. Effect of Chemical Sputtering on the Growth and Structural Evolution of Magnetron Sputtered CNx Thin Films. Thin Solid Films 2001, 382, 146-152.

(52) Rodil, S. E.; Morrison, N. A.; Robertson, J.; Milne, W. I. Nitrogen Incorporation into Tetrahedral Hydrogenated Amorphous Carbon. Phys. Status Solidi A 1999, 174, 25-37.

(53) Sharifi, T.; Hu, G.; Jia, X.; Wågberg, T. Formation of Active Sites for Oxygen Reduction Reactions by Transformation of Nitrogen Functionalities in Nitrogen-Doped Carbon Nanotubes. ACS Nano 2012, 6, 8904-8912. 
(54) Biniak, S.; Szymański, G.; Siedlewski, J.; Świtkowski, A. The Characterization of Activated Carbons with Oxygen and Nitrogen Surface Groups. Carbon 1997, 35, 1799-1810.

(55) Williams, M. W.; Arakawa, E. T. Optical Properties of Glassy Carbon from 0 to 82 Ev. J. Appl. Phys. 1972, 43, 3460-3463.

(56) Mednikarov, B.; Spasov, G.; Babeva, T.; Pirov, J.; Sahatchieva, M.; Popova, C.; Kulischa, W. Optical Properties of Diamond-Like Carbon and Nanocrystalline Diamond Films. $J$. Optoelectron. Adv. M. 2005, 7, 1407-1413.

(57) Shi, X.; Fu, H.; Shi, J. R.; Cheah, L. K.; Tay, B. K.; Hui, P. Electronic Transport Properties of Nitrogen Doped Amorphous Carbon Films Deposited by the Filtered Cathodic Vacuum Arc Technique. J. Phys.: Condens. Matter 1998, 10, 9293.

(58) Rodil, S. E.; Muhl, S.; Maca, S.; Ferrari, A. C. Optical Gap in Carbon Nitride Films. Thin Solid Films 2003, 433, 119-125.

(59) McCreery, R. L. Advanced Carbon Electrode Materials for Molecular Electrochemistry. Chem Rev 2008, 108, 2646-2687.

(60) Davies, T. J.; Compton, R. G. The Cyclic and Linear Sweep Voltammetry of Regular and Random Arrays of Microdisc Electrodes: Theory. J. Electroanal. Chem. 2005, 585, 63-82.

(61) Filipe, O. M. S.; Brett, C. M. A. Characterization of Carbon Film Electrodes for Electroanalysis by Electrochemical Impedance. Electroanalysis 2004, 16, 994-1001.

(62) Pleskov, Y. V.; Evstefeeva, Y. E.; Krotova, M. D.; Elkin, V. V.; Baranov, A. M.; Dement'ev, A. P. Electrochemical Behavior of Amorphous Carbon Films: Kinetic and Impedance-Spectroscopy Studies. Diamond Relat. Mater. 1999, 8, 64-72.

(63) Morrison, S. R. Electrochemistry at Semiconductor and Oxidised Metal Electrodes, 1st ed.; Plenum Press, 1980.

(64) Orazem, M. E.; Tribolet, B. Electrochemical Impedance Spectroscopy; Wiley, 2008.

(65) Kobayashi, K.; Takata, M.; Okamoto, S.; Sukigara, M. Ac Impedance Theory for Surface States at a Semiconductor-Liquid Junction. J. Electroanal. Chem. Interfacial Electrochem. 1985, 185, 47-60.

(66) Xiong, L.; Batchelor-McAuley, C.; Ward, K. R.; Downing, C.; Hartshorne, R. S.; Lawrence, N. S.; Compton, R. G. Voltammetry at Graphite Electrodes: The Oxidation of Hexacyanoferrate (II) (Ferrocyanide) Does Not Exhibit Pure Outer-Sphere Electron Transfer Kinetics and Is Sensitive to Pre-Exposure of the Electrode to Organic Solvents. J. Electroanal. Chem. 2011, 661, 144-149.

(67) Swaddle, T. W. Homogeneous Versus Heterogeneous Self-Exchange Electron Transfer Reactions of Metal Complexes: Insights from Pressure Effects. Chem. Rev. 2005, 105, 25732608. 
(68) Peter, L. M.; Dürr, W.; Bindra, P.; Gerischer, H. The Influence of Alkali Metal Cations on the Rate of the $\mathrm{Fe}(\mathrm{CN})_{6}{ }^{4-} / \mathrm{Fe}(\mathrm{CN})_{6}{ }^{3-}$ Electrode Process. J. Electroanal. Chem. Interfacial Electrochem. 1976, 71, 31-50.

(69) Dogonadze, R. R.; Ulstrup, J.; Kharkats, Y. I. A Theory of Electrode Reactions through Bridge Transition States; Bridges with a Discrete Electronic Spectrum. J. Electroanal. Chem. Interfacial Electrochem. 1972, 39, 47-61.

(70) Chen, P.; McCreery, R. L. Control of Electron Transfer Kinetics at Glassy Carbon Electrodes by Specific Surface Modification. Anal. Chem. 1996, 68, 3958-3965.

(71) Granger, M. C.; Swain, G. M. The Influence of Surface Interactions on the Reversibility of Ferri/Ferrocyanide at Boron-Doped Diamond Thin-Film Electrodes. J. Electrochem. Soc. 1999, $146,4551-4558$. 
TOC Graphic

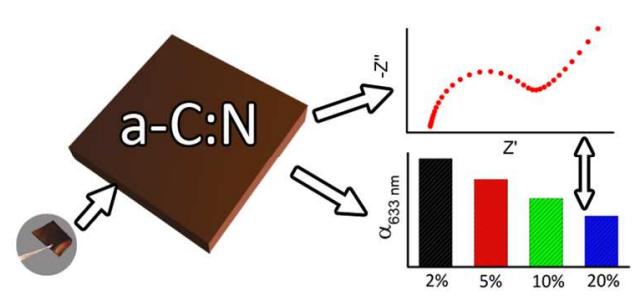

13

14

15

16

17

18

19

20

21

22

23

24

25

26

27

28

29

30

31

32

33

34

35

36

37

38

39

40

41

42

43

44

45

46

47

48

49

50

51

52

53

54

55

56

57

58

59

60

ACS Paragon Plus Environment 

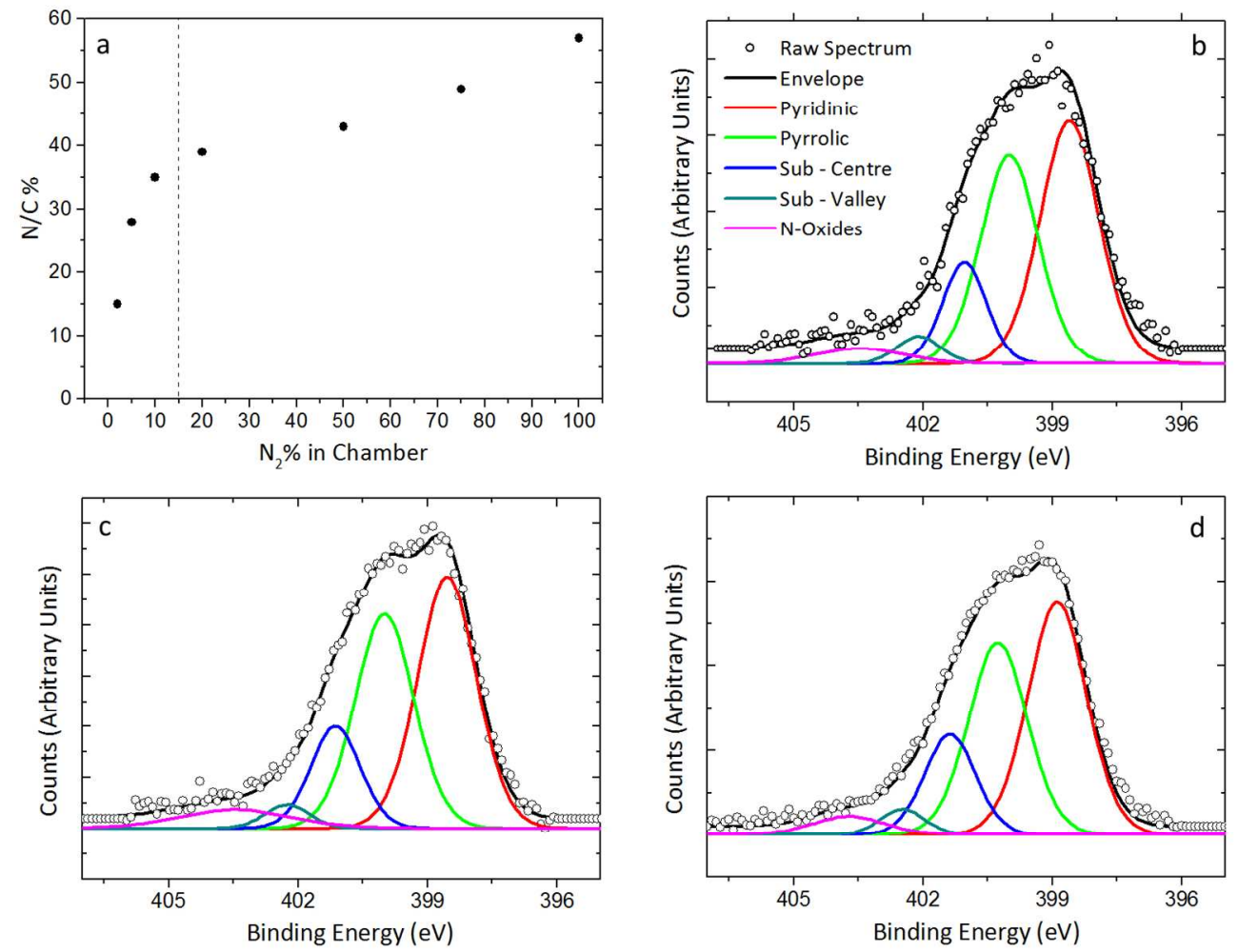

Figure 1. (a) $\mathrm{N} / \mathrm{C} \%$ versus $\mathrm{N}_{2} \%$ in the deposition gas. The dotted line delineates the two regimes of nitrogen incorporation. (b), (c), (d) Deconvoluted N 1s XPS spectra for a-C:N-2\% (b), a-C:N-5\% (c) and aC: $\mathrm{N}-10 \%$ (d). Raw spectra are shown after Shirley background substraction and offset for clarity.

Figure 1

$135 \times 105 \mathrm{~mm}(300 \times 300$ DPI $)$ 


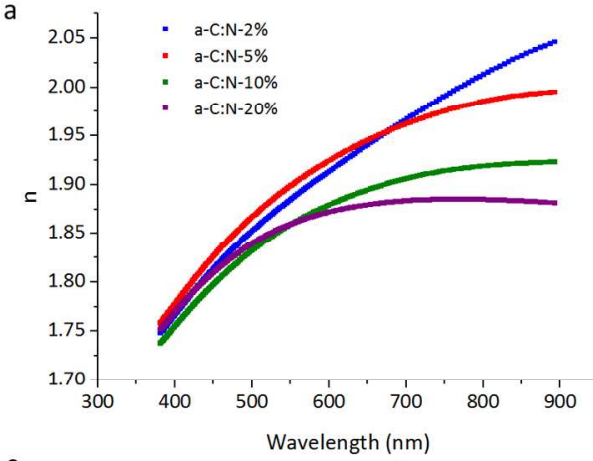

C

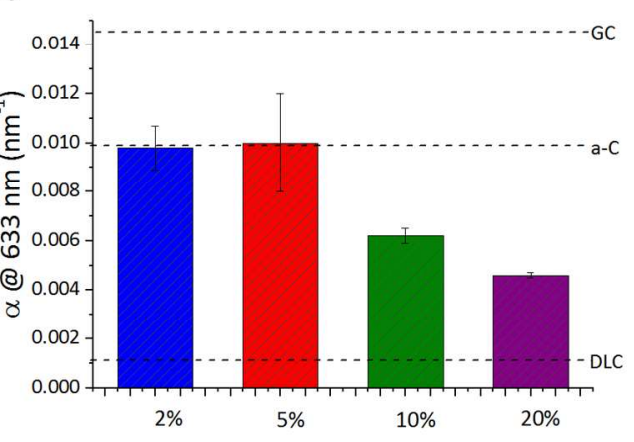

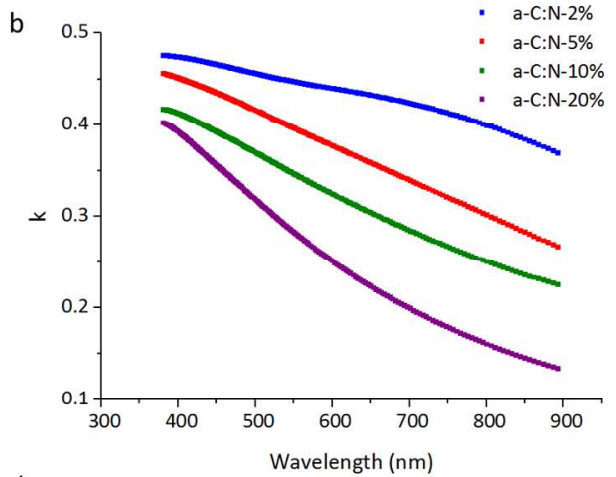

d

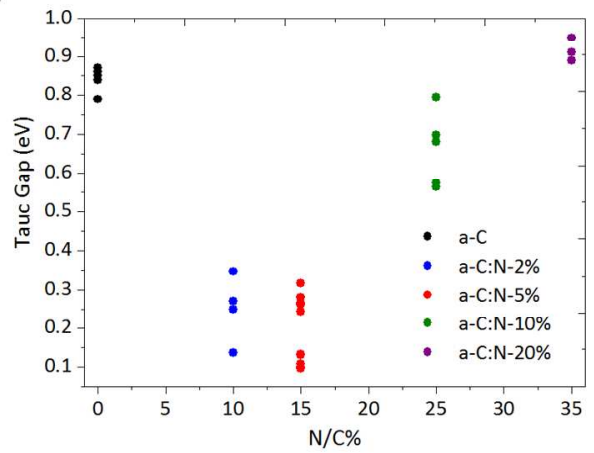

Figure 2. (a) Plots of index of refraction $(n)$ derived from SE measurements of a-C:N-2-20\% versus wavelength $(\mathrm{nm})$. (b) Plots of extinction coefficient $(\mathrm{k})$ versus wavelength for a-C:N-2-20\%. (c) Bar plot of the absorption coefficient, a @ $633 \mathrm{~nm}$ for a-C:N-2-20\%. Dotted lines refer to a-C films prepared by our group, reported GC absorptivity ${ }^{55}$ and sp $^{3}$-rich DLC films characterized by Mednikarov et al. ${ }^{56}$ (d) Cluster plot of Tauc gaps of a-C:N-2-20\% versus N/C\%. Tauc gaps of a-C films (with N/C\% $=0$ ) prepared and previously characterized by the group are also presented for comparison.

Figure 2

$147 \times 109 \mathrm{~mm}(300 \times 300 \mathrm{DPI})$ 


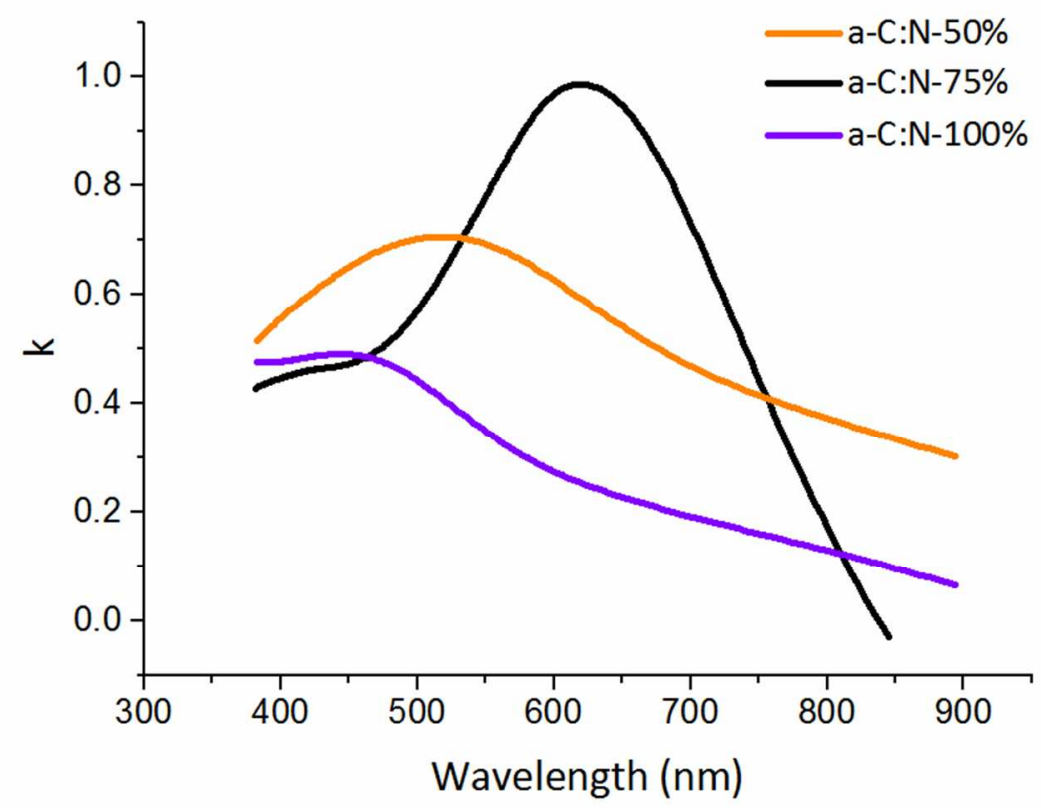

Figure 3. Extinction coefficient $(k)$ versus wavelength for a-C: $N-50 \%, 75 \%$ and $100 \%$ derived from ellipsometry measurements. Figure 3 $82 \times 57 \mathrm{~mm}(300 \times 300 \mathrm{DPI})$ 


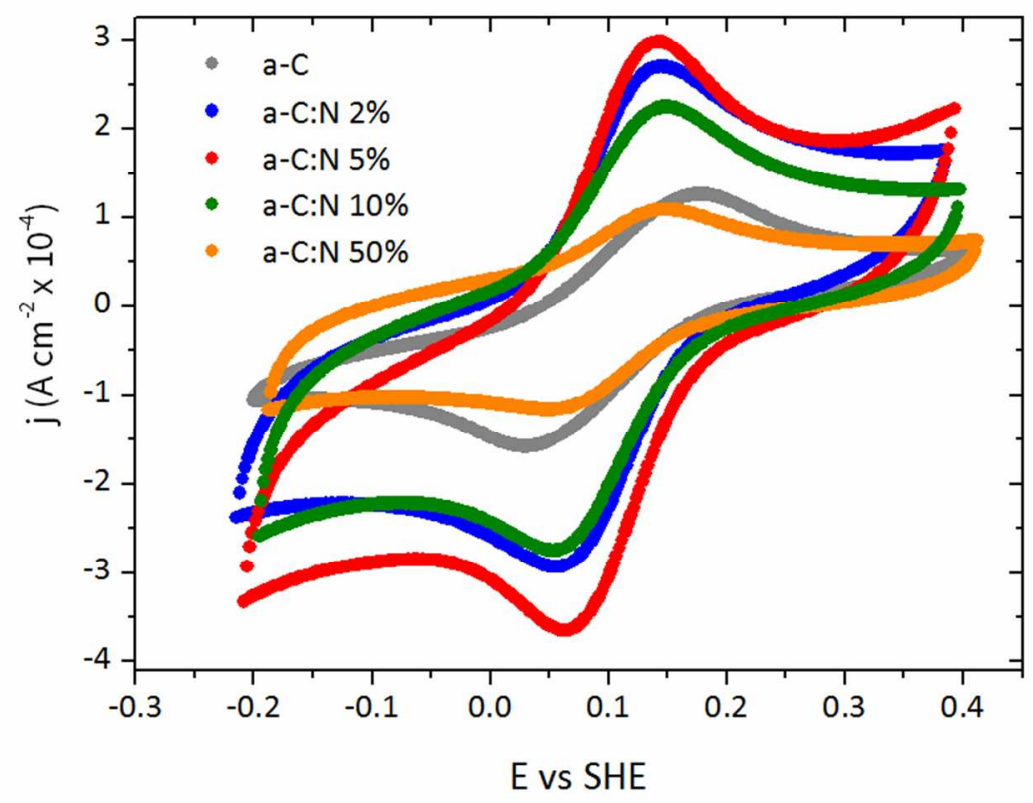

Figure 4. Cyclic voltammograms of selected a-C: $\mathrm{N}$ films in solutions of $1 \mathrm{mM} \mathrm{Ru}\left(\mathrm{NH}_{3}\right)_{6}{ }^{+2 /+3}$ in $0.1 \mathrm{M} \mathrm{KCl}$. Figure 4

$82 \times 57 \mathrm{~mm}(300 \times 300 \mathrm{DPI})$ 
Figure 5. (a) High frequency Nyquist plots for a-C and selected examples of a-C:N-X\% in $1 \mathrm{mM}$ $\mathrm{Ru}\left(\mathrm{NH}_{3}\right)_{6}{ }^{+2 /+3}$ with $0.1 \mathrm{M} \mathrm{KCl}$. (b) Plot of $\mathrm{RCT}$ versus $\mathrm{N} / \mathrm{C} \%$ for the Ruthenium redox couple. The legends in both (a) and (b) refer to the $\mathrm{N}_{2} / \mathrm{Ar} \%$ in the deposition gas during sputtering.

Figure 5

$70 \times 108 \mathrm{~mm}(300 \times 300 \mathrm{DPI})$ 


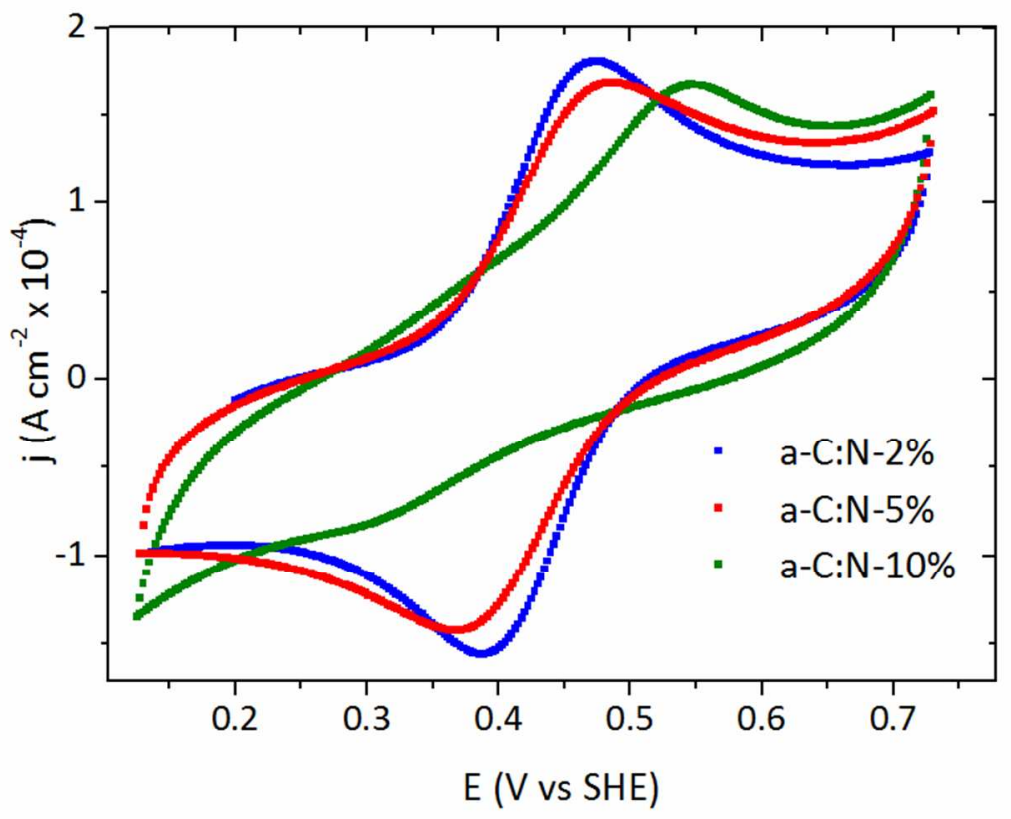

Figure 6. $\mathrm{CVs}$ of $1 \mathrm{mM} \mathrm{Fe}(\mathrm{CN})_{6}^{-4 /-3}$ in $0.1 \mathrm{M} \mathrm{KCl}$, obtained at $50 \mathrm{mV} \mathrm{s}^{-1}$ for a-C and a-C:N-2-10\%. Figure 6

$82 \times 58 \mathrm{~mm}(300 \times 300 \mathrm{DPI})$ 


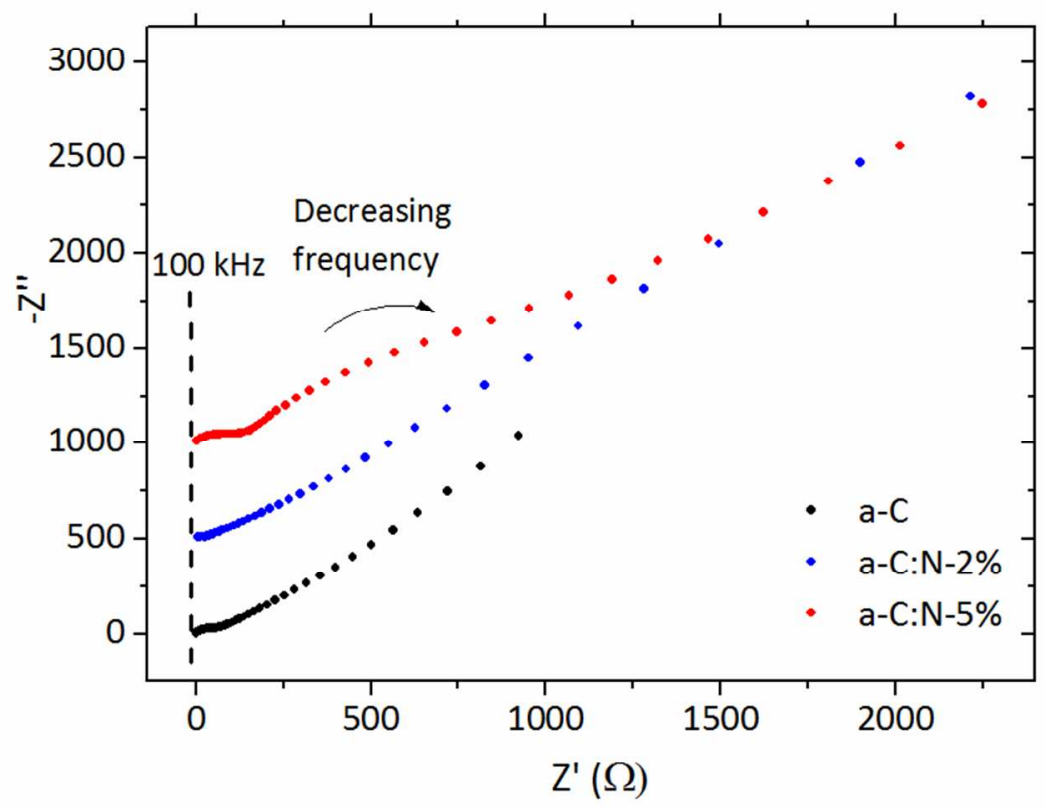

Figure 7. Nyquist plots of $1 \mathrm{mM} \mathrm{Fe}(\mathrm{CN})_{6}^{-4 /-3}$ in $0.1 \mathrm{M} \mathrm{KCl}$ obtained for a-C and a-C: $\mathrm{N}-2-5 \%$. Figure 7

$82 \times 58 \mathrm{~mm}(300 \times 300$ DPI $)$ 


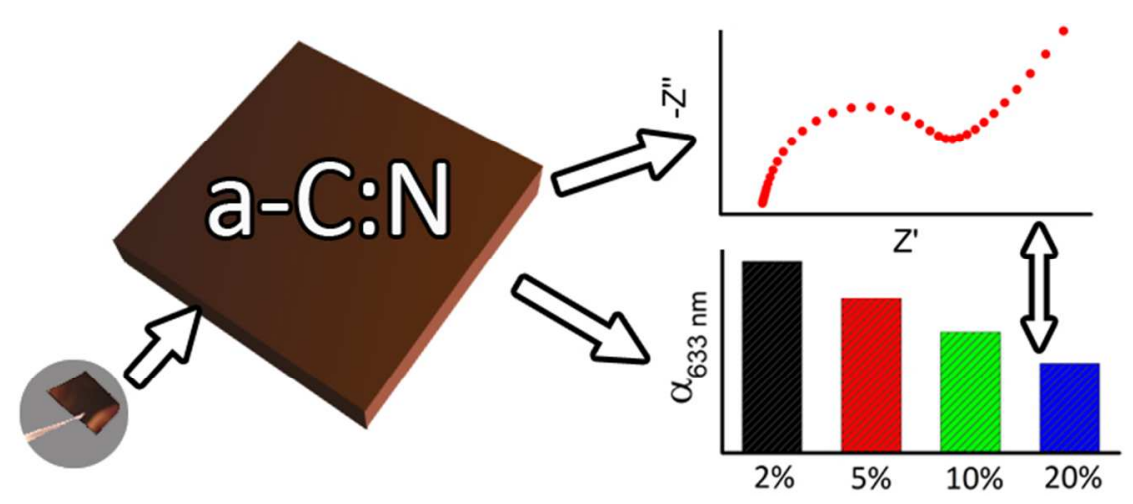

Table of Contents Graphics

Table of Contents Graphics

$74 \times 26 \mathrm{~mm}(300 \times 300 \mathrm{DPI})$ 